\title{
A ESCOLA E SEUS SILÊNCIOS: A EDUCAÇÃO EM TEMPO DE PANDEMIA ${ }^{1}$ THE SCHOOL AND ITS SILENCES: EDUCATION IN A TIME OF PANDEMIC
}

\author{
Letícia Ramires Corrêa ${ }^{2}$ e Rafael Lesses da Silva ${ }^{3}$
}

\section{RESUMO}

Esta escrita tem como intenção discutir o ensino que se põe diante dessa perspectiva até então desconhecida, esse novo meio pelo qual se dá o tramar do conhecimento que anteriormente se (re)fazia na relação com os corpos e o espaço escolar. Em tempos de pandemia professores(as), estudantes, gestores, comunidade e corpo escolar se encontram diante dessa nova reconfiguração educacional. Deste modo, alguns recortes possibilitados por meio de vivências, práticas e desafios na escola são convidados a tramarem-se e tensionar essa escrita. Diante do isolamento social foram realizados apontamentos sobre as fragilidades que poderiam envolver o ensino a distância. A pandemia apenas mostrou a verdadeira situação em que se encontram as escolas. Conclui-se que mais importante que aprontar as fragilidades da educação é da responsabilidade dos Poder Público, corpo docente, estudantes, responsáveis e comunidade escolar, uma mudança de comportamento, e traçar estratégias para a construção de uma Política educacional que respeites as demandas do campo.

Palavras-chave: Educação; COVID-19; Ensino; Pandemia.

\section{ABSTRACT}

This writing intends to discuss the teaching that is put in front of this previously unknown perspective, this new means by which the knowledge that is previously (re) done in relation to bodies and the school space takes place. In times of pandemic, teachers, students, managers, community, and school staff find themselves facing this new educational reconfiguration. In this way, some cutouts made possible through experiences, practices and challenges at school are invited to plot and tension this writing. In the face of social isolation, notes were made about the weaknesses that could involve distance learning. The pandemic only showed the real situation in which schools are. It is concluded that more important than preparing the weaknesses of education is the responsibility of the Public Power, faculty, students, guardians and the school community, a change of behavior, and to outline strategies for the construction of an Educational Policy that respects the demands of the field.

Keywords: Education; COVID-19; Teaching; Pandemic.

\footnotetext{
${ }^{1}$ Artigo.

${ }^{2}$ Doutoranda pelo Programa de Pós-graduação em Geografia pela Universidade Federal de Santa Maria. leticiarcorrea@ gmail.com

${ }^{3}$ Professor da rede estadual de ensino do Rio Grande do Sul e mestrando do Programa de Pós-graduação em Educação pela Universidade Federal de Santa Maria. E-mail: lessesrafael@gmail.com
} 


\section{INTRODUÇÃO}

Não há como separar o tempo e o espaço, sendo que os dois estão continuamente interligados, um em relação ao outro (ROCHA, 2017). Seu significado (tempo e espaço), porém, necessitou ser "ressignificado" desde o início do atual surto de coronavírus (SARS- CoV-2), causador da Covid-19. O tempo e o espaço escolar demandaram uma adaptação rápida. As demarcações do espaço/lugar que compreendíamos e nominávamos como sala de aula acabaram "borradas" e reconfiguradas diante de um novo espaço que poderíamos sinalizar como sendo "familiar pessoal". Neste sentido a sala de aula passou a ocupar os diferentes cômodos residenciais dos estudantes e professores(as), o conhecimento partilhado em meio a coletividade do espaço escolar tornou-se reduzido e individualizado.

A escola passou a ser apenas uma estrutura de concreto ou madeira "sem vida" afinal, o conhecimento não circula, não invade e preenche os espaços destes locais onde o aprendizado era algo ativo e constante, mediado pelas experiências individuais e coletivas que se davam nas relações e cruzamento das falas de estudantes e professores(as). Os livros e materiais pedagógicos continuam marcando seus lugares nas estantes/prateleiras das escolas. Entretanto, não passam de folhas de papel com imagens ou letras/palavras sobre as mais diversas tonalidades, sem os estudantes ou professores(as) de nada servem, para nada servem. Afinal, o conhecimento se dá em meio ao partilhar das experiências, conceito sublinhado por Larossa $(2002$, p. 19) etimologicamente.

Começarei com a palavra experiência. Poderíamos dizer, de início, que a experiência é, em espanhol, "o que nos passa". Em português se diria que a experiência é "o que nos acontece"; em francês a experiência seria "ce que nous arrive"; em italiano, "quello che nos succede" ou "quello che nos accade"; em inglês, "that what is happening to us"; em alemão, "was mir passiert". A experiência é o que nos passa, o que nos acontece, o que nos toca. Não o que se passa, não o que acontece, ou o que toca. A cada dia se passam muitas coisas, porém, ao mesmo tempo, quase nada nos acontece.

Deste modo torna-se possível pensar nessas experiências enquanto movimentos de um conhecimento que não é estanque, estático, mas que acontece a todo o momento em meio as relações. Posteriormente Greiner (2015) vai falar que aprendemos em relação com o outro e com os espaços. Considerando a reconfiguração dos espaços e das relações a sala de aula deu lugar à sala das residências dos alunos; o quadro verde deu lugar a tela dos computadores, celulares e tablets; o professor(a) e mediador(a) do conhecimento não está mais diante dos estudantes e sim do outro lado das telas; os pais e/ou responsáveis tornaram-se figuras importantes nesse processo, auxiliando na mediação; As demarcações do tempo não são mais os mesmos, não há o sinal do som da campainha da escola para sinalizar os intervalo, início e termino dos períodos letivos; não necessitam acordar cedo para estar no ponto de ônibus para tomar o transporte ou até mesmo se deslocar caminhando até a escola; as atividades são recebidas e realizadas no tempo de cada aluno; 
E como se dá o ensino sob essas novas reconfigurações exigidas pelo isolamento social? Como se dá essas relações entre estudantes e professores(as)? Este capítulo busca discutir o ensino no período de isolamento social, trazendo as vivências, práticas e desafios na Escola.

\section{A INTERNET E SUAS TECNOLOGIA COMO PONTE DA SALVAÇÃO}

Deparamo-nos com um combo de ferramentas tecnológicas que são apresentadas, divulgadas e vendidas como salvação para a mediação do ensino em meio a essa pandemia que se estende a nível mundial, vídeos, lives, cursos online, visam dar conta de uma demanda que afeta professores(as) e estudantes. Ferramentas que objetivam a certo modo dar seguimento ao "ensino" que fora desenhado e pensado em um momento não pandêmico.

Esta nova configuração exige ao seu modo o acesso a internet e algumas ferramentas tecnológicas básicas, porém, na prática nem sempre se aplica levando em conta que ainda existem estudantes que não têm acesso ao básico tecnológico, ou seja, a internet. Convém sublinhar que muitos estudantes encontram na escola a oportunidade de estar online, conectado a uma rede que lhe possibilite acesso a plataformas como WhatsApp, Instagram, facebook entre outros. Algo comum em escolas que se encontram distantes de grandes centros que por vezes visam contemplar estudantes que residem no perímetro rural. No entanto, ter o dispositivo telefônico não quer dizer que o aparelho tenha capacidade de armazenamento adequado para a utilização de outros aplicativos que possam vir a exigir de um maior espaço no armazenamento interno do mesmo. Da mesma forma, ter acesso a internet não quer dizer que o estudante consiga realizar pesquisas, olhar vídeos ou até mesmo interagir com professores e colegas através de aulas online. Essas questões são demandas que tendem a aumentar em contato com a realidade em que se encontram muitos estudantes e demarcar alguns caminhos que ainda se mostram tão desiguais no que se refere ao acesso a uma educação de qualidade. Lembrando que o acesso à educação não é uma "bondade" do poder público muito menos algo que deva ser "mendigado", ela é um direito de todos conforme previsto na Constituição Federal de 1988 no Capítulo III, da Educação, da Cultura e do Desporto, Seção I da Educação Art. 205:

\footnotetext{
A educação, direito de todos e dever do Estado e da família, será promovida e incentivada com a colaboração da sociedade, visando ao pleno desenvolvimento da pessoa, seu preparo para o exercício da cidadania e sua qualificação para o trabalho. [no que segue ainda, o] Art. 206. O ensino será ministrado com base nos seguintes princípios: I - igualdade de condições para o acesso e permanência na escola; II - liberdade de aprender, ensinar, pesquisar e divulgar o pensamento, a arte e o saber; III - pluralismo de ideias e de concepções pedagógicas, e coexistência de instituições públicas e privadas de ensino; IV - gratuidade do ensino público em estabelecimentos oficiais (BRASIL, 1988).
}

A pandemia veio realçar alguns silêncios na educação, nos direitos básicos que são "garantidos" pelas leis e que por vezes se mantem apenas como grifos em papeis, demarcando sua existência no 
espaço físico enquanto matéria e não enquanto relação prática com a realidade. Na Figura 1, observamos um diálogo entre professor e estudante, demostrando as dificuldades em realizar tarefas remotas:

Figura 1 - Diálogo por rede social entre professor e aluno.

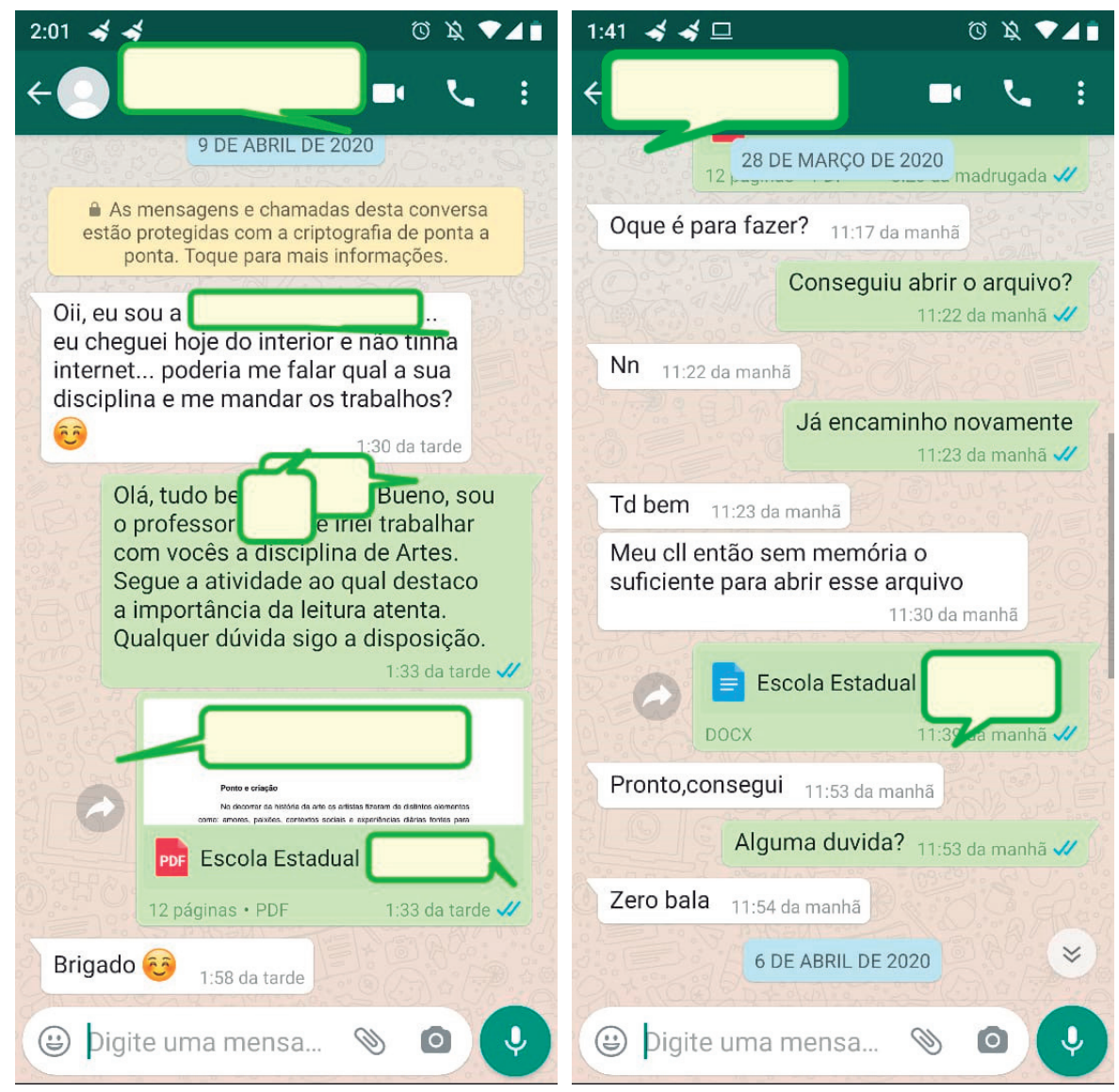

Fonte: arquivo pessoal, 2020.

Em diálogo com as imagens acima podemos mencionar o caso do menino de 13 anos morador de uma cidade de Goiás que usava o sinal de wi-fi de um açougue para poder dar segmento aos estudos durante a pandemia. Conforme a reportagem da Redação do Tribuna Jundiaí (2020):

\footnotetext{
"Willian está no oitavo ensino fundamental e, com a suspensão das aulas presenciais, passou a estudar na praça todos os dias. A família do adolescente não tem condições de manter internet e nem mesmo de comprar um aparelho celular. Para não desistir dos estudos, o garoto cata latinhas e vende, com isso, conseguiu comprar um celular e contou com a ajuda do dono do açougue que liberou a senha da rede."
}

Neste sentido a educação é colocada em fricção com a realidade das desigualdades, que tornam-se tão demarcadas em nossa sociedade. Buscar por meios de resistência que sinalizem e reafirmem a importância do ensino em meio a esse momento turbulento de pandemia em que nos encontramos objetivando a mediação de um ensino que percorre por linhas tênues e frágeis não é algo fácil. Em meio a esses movimentos alguns questionamentos ganham forma; como instigar e despertar o 
interesse do estudante em meio a mediação deste ensino a distância? Como fazer-se entender através dos meios eletrônicos? Quais ferramentas tecnológicas utilizar na preparação das aulas? Como disponibilizar o material pedagógico? Como "avaliar" as devolutivas posterior as atividades? Como trabalhar e desenvolver o conhecimento sem saber a realidade em que muitos estudantes se encontram? Como lidar com essa outra concepção de tempo que se redesenha em tempo de pandemia? Como organizar atividades pedagógicas que demandem de pesquisas na rede quando o estudante não tem acesso? São alguns dos questionamentos atuais dos professores(as), de todas as áreas da educação.

Considerando e ressaltando a importância do o professor(a) deve buscar aproximar cada vez mais os conceitos (espaço, lugar, paisagem, região e território) das vivências socioespaciais dos alunos, a fim de explicar e exemplificar situações reais de seu cotidiano (TRINDADE, 2017). Pensando sobre as sinalizações de Trindade no que refere-se a utilização de temas que envolvam o contexto atual do estudante bem como o espaço que ocupa, ressaltamos do quão importante é trabalhar com essas novas questões que afetam e que fazem parte agora do nosso cotidiano.

Se em sala de aula, com acesso direto ao livro didático e demais materiais pedagógicos, suporte básico pra o desenvolvimento das propostas manuseio e criação junto aos estudantes, comunicação com a equipe diretiva e corpo escolar, por vezes se demonstra como um desafio, o que falar sobre a realização destas tarefas a distância? Talvez um dos caminhos possíveis seja o cruzamento de temas do cotidiano pandêmico com aquilo sublinhado nos materiais didáticos pedagógicos.

\section{A ESCOLA EM ISOLAMENTO SOCIAL}

Com aumento no número de casos de coronavírus no Brasil, suspenderam-se as aulas da rede pública e privada em todo o país. A medida teve início em março e prolongou-se para os meses seguintes objetivando evitar aglomerações e deslocamentos. Quando falamos em escolas e estudantes talvez não tenhamos de imediato a noção de quantos indivíduos compõe esse sistema nacional, formado por escolas do ensino público e privado. Conforme uma pesquisa realizada pelo Instituto Nacional de Estudos e Pesquisas Educacionais Anísio Teixeira (INEP) através do censo escolar de 1 de julho de 1999 estimava-se que

Dos 35,8 milhões de alunos do ensino fundamental, 32,4 milhões (90,5\%) estudam em escolas públicas e apenas 3,4 milhões $(9,5 \%)$ em escolas particulares. No ensino médio, dos 6,9 milhões de alunos existentes, 82,4\% estão nas escolas públicas. Nas classes de educação de jovens e adultos, as escolas públicas detêm 87,3\% dos 2,8 milhões de alunos. Na pré-escola, dos 4,1 milhões de alunos matriculados, 76\% se concentram na rede pública. O setor público só não tem a maioria dos alunos na educação especial, que atende os portadores deficiências, e no ensino superior. Na educação especial, o setor público é responsável pelo atendimento de 46,8\% dos 293 mil alunos. E no ensino superior, sustenta $37,8 \%$ dos 2 milhões e 125 mil alunos. 
Os dados fornecidos pelo INEP não são recentes, entretanto, diante destas informações podemos ter uma estimativa da quantidade de indivíduos que compõe o sistema brasileiro de ensino, algo na média de 45 milhões de estudantes.

Deste modo, é necessário fazer valia das recomendações sugeridas pela Organização Mundial da Saúde (OMS), considerando que ainda não está disponível uma vacina ou medicamento especifico a ser utilizado no combate ao Covid-19 uma das melhores formas de parar a transmissão de casos é ficar em isolamento social. Sem aulas formais, as escolas têm adotado a educação a distância (EaD), com uso de computadores e atividades complementares, para dar continuidade à aprendizagem das crianças. Entretanto esta possibilidade de ensino, sinalizada enquanto único meio possível neste momento de pandemia esbarra na realidade em que se encontram muitos estudantes da rede pública de ensino.

Ao longo dos anos, o Brasil vem enfrentando muitos problemas educacionais, não é de hoje que o governo tem disponibilizado a área uma pequena fatia do "bolo" de investimentos e nos últimos anos isso tem se acentuado ainda mais. Convém destacar que a falta de investimento está também relacionada com a aprovação da Proposta de Emenda à Constituição - PEC, sancionada no ano de 2016 que prevê o congelamento de investimentos por parte do governo no âmbito da educação e da saúde por 20 anos. Atitudes que poderiam aumentar ainda mais as desigualdades sociais no Brasil conforme sinalização dos Órgãos das Nações Unidas- ONU em carta aberta ao país. O fato é que o governo e os demais órgãos responsáveis por investimentos nas áreas que são tão cruciais para o desenvolvimento intelectual e cultural de uma sociedade se isentam de suas responsabilidades. Deixam tais áreas à mercê, de privatizações como meio único de salvação. Quatro anos após a aprovação da PEC da morte como ficou conhecida, nos deparamos em meio a uma pandemia que apenas revelou o quão desigual ainda é nosso país e o quão distante estamos de possibilitar um conhecimento que esteja ao alcance de todos e todas. Não por falta de vontade do corpo docente, mas pelo desamparo de condições básicas para o partilhar do conhecimento. Parte do que colhemos hoje, como salários baixos aos educadores, infraestruturas escolares precárias, resultam de uma escolha de parlamentares e senadores que não consideraram opiniões de professores(as), estudantes, comunidade escolar que convivem diariamente nestes espaços.

Ainda que a educação seja um direto social previsto em lei, que deve ser garantida com qualidade, a qualquer indivíduo, seja ele do meio urbano ou rural. Sabe-se que isto ainda é uma realidade distante e que não está disponível para todos, especialmente para a população do campo (BELING; CANCELIER, 2019). Em tempos de Pandemia e isolamento social, em função do coronavírus (SARS- CoV-2), causador da Covid-19, essas dificuldades e problemas se agravaram, e acabaram por mostrar a verdadeira face da sucateada educação que há tempos tem sido mascarada por aqueles que deveriam incentivar e proteger esse bem tão precioso para o desenvolvimento da nossa sociedade. Formadora de distintas gerações é sobre a escola que recai a responsabilidade de transformar a sociedade (MICHELS, 2006). Deste modo, pode-se perceber a escola como um ponto de encontro, de saberes múltiplos. 
No entanto, estima-se que entre 1997 a 2018 quase 80 mil escolas do campo foram fechadas e as que ainda restaram mantiveram-se negligenciadas pelo Estado, a partir limitação de recursos (AGUIAR, 2000), o que acarretou na elevação do índice de analfabetismo, aproximadamente a 23,3\%, para aqueles acima de 15 anos (MOLINA; FREITAS, 2011). Consequentemente com o fechamento das escolas a evasão desses estudantes que tiveram de encontrar meios de se deslocarem aos centros urbanos na busca de ensino tornou-se inevitável. Neste sentido as dificuldades não estão apenas nessa busca de uma nova escola, mas também no deslocamento dos estudantes até esses espaços. Considerando que é possível encontrar prefeituras que não oferecem o suporte para o deslocamento desses estudantes até as instituições e quando oferecem por vezes são em pontos comuns que acabam distante da casa dos estudantes. Neste sentido Alentejano \& Cordeiro (2019) convém destacar que

[...] foram fechadas, sobretudo, as menores escolas e redistribuídos estudantes para as maiores, em um processo conhecido como nucleação. Uma das principais consequências disso é o aumento do tempo de deslocamento das crianças até às escolas, gerando mais cansaço e aumentando os riscos associados ao deslocamento dessas crianças entre casa e a escola

Diante desta Pandemia as escolas do campo, as que ainda resistem, entraram no isolamento social, sem transporte muitos estudantes não conseguem ir até a escola. O Estado em uma estratégia desesperada iniciou aulas á distancia que necessitam de acesso a multimídias e demais suportes tecnológicos básicos para sua execução. Estratégia que a acaba novamente negligenciando uma parcela de estudantes que não contam com tais ferramentas, espaços escolares que encontram-se para além do perímetro urbano e até mesmo escolas que não dispõem de uma infraestrutura que comporte tais tecnologias, questões existentes, tão latentes nesse momento.

Para que as aulas aconteçam, é imprescindível que o material pedagógico esteja em relação com os estudantes, necessitam chegar a todos. Mas como esse processo torna-se possível considerando que muitos estudantes ainda estão restritos a esse meio tecnológico? Do que vale considerar a existência de um dispositivo nesse processo se o mesmo não possui um pacote de acesso as redes? Como pensar em pedagogias para esses alunos que estão as margens das políticas educacionais? É valido o não cancelamento do ano letivo nessas circunstâncias em que muitos estudantes não estão tendo acesso aos materiais elaborados pelos professores(as)? Nesta nova reconfiguração onde a educação acaba mediada pelos meios digitais não é somente a escola e os estudantes que estão com dificuldades em compor essa "rede", o corpo docente também compartilha de situação semelhante considerando que uma parcela de professores(as) não possuem o básico de formação ao letramento digital para a utilização das ferramentas tecnológicas. Estamos todos diante de um ensino impar daquele até então conhecido em momentos anteriores nessa situação.

Neste sentido a pesquisa realizada pelo Instituto Península, com 7.734 mil professores(as) de todo o Brasil mesmo após seis semanas de isolamento social, considerando o período de 13 de abril e 14 de maio de 2020, aponta que $83 \%$ dos professores(as) brasileiros, em sua maioria, sentem-se nada 
ou pouco preparados para o ensino nesta nova modalidade a distância, que virou realidade em diferentes pontos do país (INSTITUTO PENÍNSULA, 2020).

Diante deste momento de isolamento social, percebe-se o quão limitadas e fragilizadas as escolas se encontram. O coronavírus fez a educação como um todo esbarrar no desafio do acesso a internet, de estar conectada à rede e na inexperiência dos professores(as) e estudantes. Sem aulas presenciais, as escolas adotaram a educação à distância $(\mathrm{EaD})$, com o uso de computadores e atividades complementares, na tentativa "desesperadora" de dar continuidade ao processo de ensino-aprendizagem dos alunos (VALADARES, 2020). Conforme sinalizado anteriormente, nem todos os estudantes do país têm acesso a computadores e à internet de qualidade. Outra realidade considerável nesse processo de aprendizagem é que muitas famílias residem em pequenos espaços e assim nesse ambiente o estudante não encontra um local "reservado" em que consiga estudar ou até mesmo ler o material pedagógico.

Manter a concentração e a rotina de estudos dos estudantes de menor idade, muitos em processo de alfabetização, enquanto os pais também trabalham em casa e/ou não conseguem atender essa demanda, talvez por não possuírem um determinado preparo especifico que está relacionado ao compartilhar da aprendizagem para ensinar os estudantes também sublinha-se enquanto desafio. Em um áudio, que transpassou as diversas redes sociais e sensibilizou muitas pessoas, um estudante do primeiro ano de uma escola do Rio Grande do Sul, relata que tem sido ajudado pela sua mãe na realização das tarefas escolares, declara:

\footnotetext{
"Oi professora tudo bem? a mãe, a mãe, não eu não. Assim, você professora sem você, professora, mas eu não consigo aprender bem. A mãe não é igual, não é igual a você. Você tem as manias de prof, a minha mãe não tem, ela trabalha no Restaurante ela só tem a mania de fazer comida. Me desculpe te incomodar agora só que eu queria falar para a senhora isso". (GAZETA WEB, 2020)
}

$\mathrm{Na}$ fala, o estudante a seu modo relata sobre a falta que a professora faz, com os desafios de ter que realizar os estudos em casa, contando com a ajuda de sua mãe, que não possui formação profissional para orientado-lo. Mesmo com todos esses desafios os professores(as) e demais espaços educativos continuam buscando meios de articulações e resistência nesse momento tão difícil, afinal, sabem do quão importante e precioso é esse bem chamado de "educação" que infelizmente as vezes se mantem apenas em discursos e lei que diante da realidade, no chão de escola, não se sustentam, por falta de recursos.

\section{LACUNAS: ENTRE LEIS E A REALIDADE}

Podemos compreender a lei como um conjunto de normas, diretrizes e regras que objetivam organizam e autorizam corpos a viverem em sociedade. Estas se fazem vivas na maquinaria social e atravessam as mais distintas esferas educacionais, econômicas, sociais e educacionais. 
Diante desses elementos sabe-se das mudanças que ocorreram nas políticas educacionais em virtude das demandas econômicas surgidas ao logo desses anos, que acabaram acarretando em alterações nos sistemas de ensino em esfera municipal, estadual e federal (OLIVEIRA, 2001). A educação sempre pareceu estar a serviço de uma sociedade melhor, vista como principal formadora de indivíduos dentre outras responsabilidades atribuídas a mesma. Tanto que a um certo tempo a educação básica era compreendida como uma garantia de participação no mercado de trabalho (OLIVEIRA, 2001). De tal modo:

\begin{abstract}
A gestão democrática como princípio da educação nacional, presença obrigatória em instituições escolares, é a forma não violenta que faz com que a comunidade educacional se capacite para levar a termo um projeto pedagógico de qualidade e possa também gerar "cidadãos ativos" que participem da sociedade como profissionais compromissados e não se ausentem de ações organizadas que questionem a invisibilidade do poder (CURY, 2011, p. 15).
\end{abstract}

Cidadãos ativos? Então porque os corpos são comportados em espaços demarcados? Eles são contemplados/ouvidos no próprio currículo escolar? Que cidadãos ativos são esses que são calados/ submetidos a lei da punição dentro o espaço escolar? De que modo essas letras da lei são (re)configuradas na escola? Como a gestão escolar pensa/contempla essas implementações das leis?

Diante disso, é neste contexto educacional que se faz necessário que os profissionais que compõem esse corpo escolar tenham noções da importância da sua participação, do seu próprio trabalho, diante da dinâmica de cada instituição, bem como no planejamento do processo pedagógico (LÜCK, 2011). Neste sentido está mesma autora (2011, p. 21) pontua que

\footnotetext{
Há uma clara percepção, por parte de lideranças brasileiras, de representantes dos mais diversos segmentos que compõe a nossa sociedade, de comunidades e famílias, de que a melhoria da qualidade de vida, o desenvolvimento das comunidades e a transformação do Brasil em uma nação desenvolvida, cidadã e realizada, somente se dará caso consigamos promover, o mais urgentemente possível, um salto de qualidade em nossa educação.
}

Diante disso, essas redes sociais, econômicas e ideológicas se tramam com a escola que parece estar empenhada na formação de cidadãos melhores. Afinal, é sobre ela que recai o peso do desenvolvimento social. E para que isso (talvez) aconteça algumas leis acabam sendo criadas ou até mesmo reformuladas para que sirvam de suporte (obrigatoriedade) a escola. Como é o caso da reformulação da Lei de Diretrizes e Bases n 9.394, em 2013 que passou a tornar obrigatória e gratuita a educação básica dos quatro aos dezessete anos de idade. Entretanto, ainda o que vemos destas relações das leis x educação x escola são inúmeras lacunas que na prática e realidade escolar (muitas leis) não se sustentam, não facilitam, protegem ou fomentam a educação como descrito nas formas das leis.

A Pandemia permite observar claramente as diversas dificuldades da sociedade e suas múltiplas espacialidades dos sujeitos que não apenas vivem, mas constroem o espaço (AMPARO, 2020). Neste sentido percebe-se as demarcações na construção deste espaço, enquanto determinada classe tem a possibilidade de realizar o isolamento social com seus familiares em praias particulares e 
fazendas restritas, outra parcela de brasileiros mantem-se em um outro paralelo o das comunidades. Formadas por aglomerações habitacionais como é o caso da Rocinha na Zona Sul do Rio de Janeiro considerada a maior comunidade do país, com 69.161 habitantes em 23.352 domicílios. Da mesma forma que é do Brasil a maior favela da América Latina, localizada em Sol Nascente no Distrito Federal com 79 mil habitantes. Espaços que sinalizam imensos abismos sociais, realidade de uma grande parcela de brasileiros que empresários e políticos acabam por negar e não considerar em políticas inclusivas ou de auxílio assistenciais a essas famílias.

Assim, enquanto alguns aparecem defendendo a continuidade de um sistema que claramente não funciona, no qual a solidariedade é reduzida a ações de caridade, outros estão, efetivamente, utilizando a pandemia para refletir sobre nossa vulnerabilidade como espécie (BITTENCOURT, 2020). Bem como o potencial catastrófico das grandes epidemias históricas, como a gripe espanhola (sec. XX) ou a peste bulbônica (sec. XIII) e a tuberculose (século XIX).

Diante desse cenário pandêmico, os professores(as) buscam dar continuidade ao processo de ensino-aprendizagem com os estudantes, para que possam continuar compreendendo, questionando e interpretar criticamente a realidade em que vive. Compreensões que ajudam os estudantes a construírem um domínio de elementos que dão significado aos processos individuais e coletivos de aprendizagem que permitem a seu modo ler o mundo e partindo disso desenvolva um pensamento crítico sobre a atualidade e aquilo que compõe seu cotidiano.

\section{CONSIDERAÇÕES FINAIS}

Pode-se observar que é de extrema importância o papel da escola e sua aproximação com a comunidade escolar, mantendo diálogos constantes, para assim, poder conhecer as especificidades, dinâmicas, limites, possibilidades e alternativas para as práticas pedagógicas. Que devem ser voltadas e planejadas, para o lugar que os alunos estão inseridos, sua realidade, respeitando e valorizando seus saberes sociais, pois a educação do campo deve ser pensada a partir do contexto em que a escola está inserida, com intuito de atender as reais necessidades e anseios da comunidade, principalmente nesse período de isolamento social.

As consequências dessa pandemia em relação a educação, dificilmente serão analisadas com precisão durante o pico da pandemia no Brasil. Pois, os alunos permanecem com as atividades enviadas via Facebook, e-mail, Whatsapp, ou no caso de algumas escolas entregues e impressas pela Secretaria de Educação do Município.

Embora acredita-se que essas atividades sejam desenvolvidas sem acompanhamentos docentes, dificilmente se comparam com as aulas presenciais. Devido às incertezas do tempo de retorno às aulas e o volume que essas proporcionarão com o decorrer da gravidade da propagação do vírus, não sabe-se como serão administradas essas atividades. 
Portanto, pais, alunos e professores que tiveram suas rotinas alteradas no ano letivo de 2020, por conta da Pandemia (SARS-CoV2), sentiram a importância dos quatros pilares da educação, ou seja, aprender a conhecer, fazer, viver e ser. De fato, as dificuldades e os problemas da educação brasileira sempre existiram, a diferença é que foram somadas a outros problemas de amplitudes mundiais, que mostraram a verdadeira face da educação no país.

O questionamento que fica nesse momento é, como ficará a educação após o fim do isolamento social provocado pelo coronavírus? Servirá apenas para impulsionar novas políticas públicas que sejam compatíveis com a realidade escolar? Será que esses espaços serão assistidos conforme suas necessidades e demandas? Será que a escola novamente trará à tona a importância da sua própria existência? Será que o reconhecimento social, bem como da família sobre a permanência dos estudantes na escola irá ser reforçado? Será que o professor(a) enquanto presença física no espaço escolar terá seu reconhecimento como mediador de extrema importância do conhecimento?

Por fim, pode-se concluir que os resultados dessa pandemia serviram para mostrar o quanto a escola exerce um papel fundamental na vida do estudante, por inseri-los ao convívio social; por mostrar a relevância do papel da professora e do professor como mediador e articulador, e que repense na relevância da formação inicial e continuada em relação ao uso novas tecnologias para o ensino. Mais importante do que apontar os problemas, é da responsabilidade dos Poder Público, corpo docente, alunos, responsáveis e comunidade escolar uma mudança de comportamento, sensibilizar-se e ter consciência que, educar vem atrelado a uma ação. E esta ação inclui fazer falar-se no silêncio, expor esses silêncios. Silêncios que ainda não somos capazes de identificar e nomear, fazendo-os existirem. Silêncios que classificamos e construímos discursivamente. Silêncios como algo desejado, exigido, conquistado, imposto, mas que também é algo que incomoda, que serve à resistência ao conforto.

\section{REFERÊNCIAS}

ALENTEJANO, Paulo; CORDEIRO, Tássia. 80 mil escolas no campo brasileiro foram fechadas em 21 anos. 2019. Disponível em: https://bit.ly/35thzkL. Acesso em: 28 de julho de 2020.

AMPARO, Sandoval. Pandemia e Geograficidade: da expansão do Coronavírus às estratégias de prevenção. 2020. Disponível em: https://bit.ly/35sy6VU. Acesso em: 25 de maio de 2020.

BELING, H. CANCELIER, J. W. A importância do lugar no contexto da escola do campo. In: FOLMER, Ivanio; MACHADO, Gabriella Eldereti (Orgs.). Educação do campo e contextos de ensino e aprendizagem. Rio de Janeiro: Dictio Brasil, 2019. 
BITTENCOURT, Renato Nunes. Pandemia, isolamento social e colapso global. Revista Espaço Acadêmico, n. 221, 2020. Disponível em: https://bit.ly/38D237X. Acesso em: 25 de maio de 2020.

BRASIL. Constituição da República Federativa do Brasil de 1988. Brasília, DF: Presidência da República, [2020]. Disponível em: https://bit.ly/39q1QnL. Acesso em: 28 de julho de 2020.

CURY, Carlos, Roberto, Jamil. Gestão democrática dos sistemas públicos de ensino. In: OLIVEIRA, M. A. M. (Org.). Gestão educacional: novos olhares, novas abordagens. 8. ed. p. 15-21, Petrópolis, RJ: Vozes, 2011.

GAZETA WEB. 2020. Professora chora ao ouvir áudio de aluno. Disponível em: https://www. youtube.com/watch?v=14fuJjlNAN8. Acesso em 19 de maio de 2020.

INEP - INSTITUTO NACIONAL DE ESTUDOS E PESQUISAS EDUCACIONAIS ANÍSIO TEIXEIRA. Indicadores Educacionais. Disponível em: https://bit.ly/2K8coiG. Acesso em: 28 de julho de 2020.

INSTITUTO PENÍNSULA. 2020. Em quarentena: 83\% dos professores ainda se sentem despreparados para ensino virtual. Disponível em: https://bit.ly/38yRliM. Acesso em: 18 de maio de 2020.

LAROSSA, Jorge B. Notas sobre a experiência e o saber de experiência. Rev. Brasileira de educação [online], n.19, p. 20-28, 2002.

LÜCK, Heloísa. Gestão Educacional: Uma questão paradigmática. 9. ed. Petrópolis, RJ: Vozes, 2011. MICHELS, Helena, Maria. Gestão, formação docente e inclusão: eixos da reforma educacional brasileira que atribuem contornos à organização escolar. Rev. Brasileira de Educação, v. 11, n. 33, p. 406-560, 2006.

MOLINA, M. C. C.; FREITAS, H. C. de A. Avanços e desafios na construção da educação do campo. Em Aberto, Brasília, v. 24, n. 85, p. 17-31, abr. 2011.

OLIVEIRA, Alaíde Paulino Machado de. Ideologia e educação: a proposta pedagógica do MST e as escolas de campo de Querência do Norte-Pr. 2006. Dissertação (Mestrado em Geografia Humana) Universidade Estadual de Maringá, Programa de Pós-Graduação em Geografia, Maringá, 2006. 
OLIVEIRA, Dalila Andrade. Política educacional nos anos 1990: educação básica e empregabilidade. In: DOURADO, Luiz F.; PARO, Victor H. (Org.). Políticas Públicas Educação Básica. São Paulo: Xamã. V. 01. 2001, p. 105-122.

REDAÇÃO TRIBUNA JUNDIAÍ. Menino de 13 anos usa Wi-Fi de açougue para estudar durante pandemia. Disponível em: https://bit.ly/2LjPWn6. Acesso em: 28 de julho de 2020.

ROCHA, L.B. Novas configurações geográficas a partir do tempo e do espaço. In: TRINDADE, Gilmar Alves et al. (Orgs.). Geografia e ensino: dimensões teóricas e práticas para a sala de aula. Ilhéus, BA: Editus, 2017.

TRINDADE, Gilmar Alves. Aplicação dos conceitos geográficos no ensino fundamental e médio. In: TRINDADE, Gilmar Alves et al. (Orgs.). Geografia e ensino: dimensões teóricas e práticas para a sala de aula. Ilhéus, BA: Editus, 2017. 
